\title{
Preventive effects of a mixture of micronutrients with antioxidative properties on experimentally induced prostate hyperplasia
}

\author{
Torricelli P. ${ }^{1}$, Ferorelli P. ${ }^{2}$, De Martino A. ${ }^{2}$, Antonelli F. ${ }^{2}$, Beninati S. ${ }^{2, *}$ \\ ${ }^{1}$ Department SPES, University of Molise, Campobasso, Italy \\ ${ }^{2}$ University of Rome, Tor Vergata, Dept Biology, Roma, Italy
}

\section{Email address:}

beninati@bio.uniroma2.it (Beninati S.)

\section{To cite this article:}

Torricelli P. , Ferorelli P., De Martino A., Antonelli F. . Beninati S. . Preventive Effects of A Mixture of Micronutrients with Antioxidative Properties on Experimentally Induced Prostate Hyperplasia, American Journal of Life Sciences. Vol. 1, No. 1, 2013 , pp. 22-26. doi: 10.11648/j.ajls.20130101.14

\begin{abstract}
A mixture of antioxidants found in a commercial food supplement called Citozym (CIZ), showed a preventive capability on experimental prostate hyperplasia induced by testosterone propionate (TP) in C57BL6/N mice. Treatments by CIZ were given orally and started 10 days before the induction of prostate hyperplasia. TP significantly increased prostate size and weight ratio, and this induced increase was significantly inhibited in CIZ-treated mice in comparison with positive controls in a dose-dependent manner. We conclude that CIZ can prevent TP-induced prostate hyperplasia and therefore may be beneficial in the management of benign prostatic hyperplasia.
\end{abstract}

Keywords: Antioxidants, Micronutrients, Benign Prostatic Hyperplasia

\section{Introduction}

Benign prostatic hyperplasia (BPH) is an hormone- and age-related disease, characterized by histological changes and variable increases in prostatic size (1). Since epidemiological data suggest that the incidence of BPH in Asian men increases after adopting a western lifestyle (2), dietary factors likely play a role in the development of BPH. Indeed, a diet rich in fruit and vegetables may also reduce the occurrence of BPH (3). It was suggested that he beneficial effect of natural and dietary elements with antioxidant properties on the risk of prostate cancer, which has been observed in epidemiological studies, may occur at early preneoplastic stages of the natural history of the disease.(4) In recent years, natural antioxidants found in fruits, beverages (fruit juice, wine, tea, chocolate, etc.), and to a lesser extent vegetables, dry vegetables, and cereals, have been reported to play a role in the prevention and/or the treatment of various diseases associated with oxidative stress such as cancer, cardiovascular diseases, and inflammation (5). Antioxidants are reducing agents, such as vitamin C, vitamin $\mathrm{E}$, and carotenoids, they protect the tissues of the body against oxidative stress (6) The considerable diversity of their structures affects their biological properties: bioavailability, antioxidant activity, and specific interactions with cell receptors and enzymes like $5 \alpha$-reductase, which catalyzes the conversion of testosterone to dihydrotestosterone and which is implicated as a causative factor in $\mathrm{BPH}$ (7). We have recently reported that a commercial mixture of antioxidants (CIZ) found in a commercial food supplement, protected C57BL6/N mice from melanoma carcinogenesis, when chronically given before the initiation and promotion phases of melanoma cancer (8). The aim of this study was to investigate the preventive effects of CIZ against TP-induced prostate hyperplasia in male C57BL6/N mice. CIZ was given orally 10 days before the induction of prostate hyperplasia in C57BL6/N mice and during the 30 days of induction of this pathology. Body and prostate weight and serum PSA levels of mice were recorded during the experiment in order to determine the effects of the preventive treatments with CIZ in TP-induced BPH.

\section{Materials and Methods}

\subsection{Chemicals}

Testosterone propionate was purchased from SigmaAldrich (St. Louis, MO, USA). The commercial mixture of antioxidants (CIZ) was a gift from Citozeatec (Citozeatec S.r.l. Peschiera Borromeo, Milano, Italy). The main com- 
ponents of CIZ are as follows (units/100 g): $500 \mathrm{mg}$ of vitamin C, $56 \mathrm{mg}$ of vitamin B5,56 $\mu \mathrm{g}$ of vitamin D, 3,3 $\mathrm{mg}$ of vitamin B9, $222 \mathrm{mg}$ of pyruvic acid, $120 \mathrm{mg}$ of citric acid, $250 \mathrm{mg}$ of tartaric acid and $77.8 \mathrm{~g}$ of carbohydrates.

\subsection{Induction of Prostate Hyperplasia}

BPH was induced by subcutaneous injections of TP at a dose of $2 \mathrm{mg}$ /day per mouse, once a day for 30 days from Day 11 to Day 40. TP was dissolved in olive oil (OO) each day before administration to the animals.

\subsection{Determination of Serum Testosterone Concentration}

Testosterone levels of individual animals of each group were measured every 5 days using a testosterone ELISA kit. The effect of the test samples on the serum testosterone levels was measured using an ELISA reader (Bioline BPR08). Blood was collected from the retro-orbital plexus of mice and centrifuged at $2500 \times \mathrm{g}$ for $15 \mathrm{~min}$. The UBI Magiwel testosterone quantitative test used is based on a competitive solid phase enzyme immunoassay. The test sample competes with enzyme-labeled-testosterone for a fixed and limited number of antibody sites on the microtiter wells. In the assay procedure, the testosterone standard or test serum is incubated with the testosterone antibody and the testosterone-horseradish peroxidase conjugate in the antirabbit IgG coated well. In this solid-phase system, the antibody bound testosterone will remain on the well while unbound testosterone will be removed by washing. A color is developed when tetramethylbenzidine (TMB) substrate is mixed with the antibody bound testosterone-horseradish peroxidase enzyme conjugate. After a short incubation, the enzyme reaction is stopped and the intensity of the color is measured with a microreader at $450 \mathrm{~nm}$.

\subsection{Determination of Serum Prostate Specific Antigen Levels}

Prostate specific antigen (PSA) levels were measured for individual mice of each group to find the severity of hyperplasia induced in the prostate by TP treatment. For this purpose a PSA ELISA kit was utilized (Cusabio Biotech Co. Ltd, Newark, Delaware, USA). The PSA ELISA kit is intended for the quantitative determination of total PSA. The PSA was quantified by a published method (9). The PSA ELISA is a solid-phase, non competitive immunoassay based upon the direct sandwich technique. Calibrators, controls and samples were incubated together with biotinylated anti-PSA monoclonal antibody and horseradish peroxidase (HRP) labelled anti-PSA monoclonal antibody in streptavidin-coated microtiter strips. After washing, buffered substrate (TMB-HRP substrate) which contains hydrogen peroxide and chromogen reagent $\left(3,3^{\prime}, 5,5^{\prime}\right.$ tetra methyl benzidine) was added to each well and the enzyme reaction was allowed to proceed. The color intensity was determined in the microtiter plate spectrophotometer at 620 $\mathrm{nm}$. Calibration curves were constructed for each assay by plotting absorbance versus the concentration of each cali- brator. The PSA concentration of samples was then read from the calibration curve.

\subsection{Experimental Protocol}

Male C57BL6/N mice (80) of 13 weeks of age and a body weight of about 25/35 g were divided in four groups of 20 animals each. Group A received only subcutaneous injections of $\mathrm{OO}$ for 30 days (negative control). Group B was treated with TP injected subcutaneously for 30 days (positive control). Group $\mathrm{C}$ was pretreated by oral administration of $5 \mathrm{~mL} /$ day of CIZ, diluted $1: 2 \mathrm{v} / \mathrm{v}$ with physiological solution (PS) for 10 days and with CIZ (1:2 v/v) and TP for the successive 30 days. Group D was pretreated by oral administration of $5 \mathrm{~mL} /$ day of CIZ, diluted 1:4 v/v with PS for 10 days and with CIZ $(1: 4 \mathrm{v} / \mathrm{v})$ and with TP for the successive 30 days. These doses were selected from previous dose-response studies. Briefly, treatments with CIZ started 10 days prior to the induction of prostate hyperplasia by TP and were given daily. 24 hours after the last treatment with CIZ and TP, C57BL6/N mice were sacrificed under anesthesia, the prostate, bladder, and seminal vesicles were removed. The prostate was carefully dissected away from the bladder and seminal vesicles, and the wet weight of the whole prostate was determined. Sample of prostate lobes were examined by histological procedures (data not shown).

\subsection{Statistical Analyses}

The statistical analysis was performed using the MannWhitney U test for intergroup comparisons. Spearman's rank correlation test and the linear regression analysis were performed to analyze correlations between groups $\mathrm{B} / \mathrm{C}$ and $\mathrm{B} / \mathrm{D}$ and the duration of administration of CIZ and to draw least squares regression lines. Values were expressed as the mean \pm SD. $P<0.05$ was regarded as statistically significant

\section{Results}

\subsection{Effects of Treatments with CIZ on Prostate Weight and Prostate Weight/Body Weight Ratio of C57BL6/N Mice}

As shown in Table I, the prostate weights (PW) of C57BL6/N mice of the four groups of treatment taken at the end of the study were statistically different. The PW of mice of the negative control (group A) was significantly lower $(50.6 \pm 3.29 \mathrm{mg})$ than that of the positive control (group B) receiving subcutaneous injections of $\mathrm{TP}$ $(84.9 \pm 6.0 \mathrm{mg})$. The PW of the group C $(48.5 \pm 7.2 \mathrm{mg})$ was significantly lower than that of the positive control group B and of the group $\mathrm{D}(74.2 \pm 4.3 \mathrm{mg})$. The prostate weight/body weight ratio express as $\mathrm{mg} \mathrm{PW} / 100 \mathrm{~g}$ of $\mathrm{BW}$ (PW/BW) of C57BL6/N mice for the negative control (group A) was significantly lower (158.2 $\pm 12.8 \mathrm{mg}$ $\mathrm{PW} / 100 \mathrm{~g}$ of $\mathrm{BW}$ ) than that of the positive control (group B) receiving subcutaneous injections of TP ( $303.2 \pm 20.1$ 
mg PW/100 g of BW). The PW/BW of group C receiving an oral pretreatment with CIZ diluted 1:2 and subcutaneous injections of TP were significantly lower $(134.7 \pm 11.0 \mathrm{mg}$ $\mathrm{PW} / 100 \mathrm{~g}$ of $\mathrm{BW})$ than that of the positive control group B. No statistical differences were observed between the PW/BW of group D ( $296.8 \pm 23.5 \mathrm{mg} \mathrm{PW} / 100 \mathrm{~g}$ of BW) receiving an oral pretreatment with $\mathrm{CIZ}$ diluted 1:4 and subcutaneous injections of TP and the positive control group B.

Table 1. Effects of TP and CIZ treatments on prostate weight (PW) and prostate weight/body weight (PW/BW) of C57BL6/N mice.

\begin{tabular}{lll}
\hline Treatment & PW & PW/BW \\
\hline group & $\mathbf{( m g )}$ & $\mathbf{( m g ~ P W / 1 0 0 ~ g ~ o f ~ B W ) ~}$ \\
\hline A (negative control) & $50.6 \pm 3.2$ & $158.2 \pm 12.8$ \\
B (positive control) & $84.9 \pm 6.0$ & $303.2 \pm 20.1$ \\
C (CIZ 1:2/TP) & $48.5 \pm 7.2^{*}$ & $134.7 \pm 11.0^{*}$ \\
D (CIZ 1:4/TP) & $74.2 \pm 4.3$ & $296.8 \pm 23.5$ \\
\hline
\end{tabular}

Data are the mean of three determinations $\pm S D$

$*(p<0.05)$

\subsection{Effects of Treatments with CIZ On PSA Serum Le- vels Of C57BL6/N Mice}

The PSA serum levels are abnormally elevated in patients with prostate cancer, BPH and patients with prostate inflammatory conditions (9). The effect of the administration of TP on the PSA levels of C57BL6/N mice is an indication of the hypertrophy of the prostate induced by TP. This parameter was measured in the serum of the test animals of various groups using the PSA ELISA kit. As shown in Fig. 1, the normal PSA level in the vehicle (OO) treated mice (group A) was found to be $0.220 \pm 0.094 \mu \mathrm{g} / \mathrm{L}$. The PSA level increased to $1.690 \pm 0.322 \mu \mathrm{g} / \mathrm{L}$ in the TPtreated animals (group B). The CIZ- treated mice, group $\mathrm{C}$ and $\mathrm{D}$, showed a decrease in the PSA level to $0.588 \pm$ $0.102 \mu \mathrm{g} / \mathrm{L}$ and to $1.103 \pm 0.224(\mathrm{p}<0.05)$ respectively, compared with the TP-treated group B. The untreated mice showed a PSA levels of $0.279 \pm 0.123$. These observations indicate the preventive effects of CIZ on TP-induced hyperplasia.

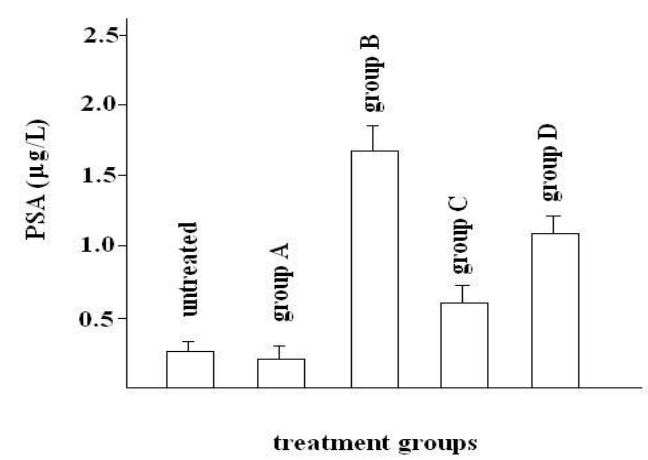

Figure 1. Effects of TP and CIZ on serum PSA levels of C57BL6 mice. Data are the mean of three different determinations $\pm S D *(p<0.05)$.

\section{Discussion}

In the ageing man BPH is the common health problem and involves hormonal changes (10). The enzymatic conversion of testosterone into its more active metabolite dihydrotestosterone (DHT) is localized in the prostate. DHT binds to androgenic receptors and promotes protein synthesis and cellular growth and is responsible of the androgen stimulation of the prostate gland leading to the development of BPH. It is well known that free radicals and reactive oxygen species (ROS) are produced more with advancement of age leading to oxidative stress (11).

Oxidative stress, cause extensive damage to various organ in the body and may be associated with pathogenesis of BPH. Since it reproduces adequately, the major features of human BPH, including functional and histological changes, prostate enlargement induced by testosterone, has been experimentally used to assess the effects of potential pharmacological treatments for BPH (12). This study investigated whether oral dosing with a commercial mixture of antioxidants (CIZ) rich in vitamins $\mathrm{C}$ and $\mathrm{D}$, pyruvic, citric, and tartaric acids, would prevent $\mathrm{BPH}$ induced by TP in mice. The positive effects of CIZ found here are consistent with the presence of these components. Indeed, several evidences support the notion that vitamin $\mathrm{C}$ is involved in the pathogenesis of BPH. For instance, case-control studies have demonstrated that men who consume fruits and vegetables rich in vitamin $\mathrm{C}$ have a lower incidence of $\mathrm{BPH}$ (13-14). Furthermore, vitamin C plasma concentrations were found to be significantly lower in $\mathrm{BPH}$ patients than in normal healthy controls (15). Accordingly, clinical studies suggest that vitamin $\mathrm{C}$ lowers the risk of $\mathrm{BPH}$ development, and because vitamin $\mathrm{C}$ generally acts to reduce oxidative stress, it might be expected that it influences the development of BPH. A growing body of evidence suggests that the biological effects of vitamin $\mathrm{C}$ are due to its specific targeting of cell signaling and gene regulation systems. Indeed, vitamin $C$ is known to repress various transcription factors, such as IRF and NF- $\kappa \mathrm{B}$, and to suppress their downstream genes (16-18). In addition, HIF-1 $\alpha$ inhibition by vitamin $\mathrm{C}$ has been reevaluated because vitamin $\mathrm{C}$ initiates HIF-1 $\alpha$ degradation by activating PHDs. In particular, a tumor xenograft study demonstrated that vitamin $\mathrm{C}$ has in vivo anticancer activity by targeting HIF-1 $\alpha$ (19) and other studies have also shown that vitamin $\mathrm{C}$ has HIF$1 \alpha$ inhibitory effects in various tumor cells (20-21). Vitamin D insufficiency has been suggested as a risk factor for prostate cancer (22-24). Ahonen et al (25) reported that prostate cancer risk, analyzed by quartiles of the $25(\mathrm{OH}) \mathrm{D}$ levels, was inversely related to $25(\mathrm{OH}) \mathrm{D}$ level. In addition, a low vitamin D level was associated with a higher likelihood of having prostate cancer diagnosed at younger age and with more advanced stage. Recently, Tretli et al (26) suggested that serum vitamin $\mathrm{D}$ levels have a prognostic significance for patients with prostate cancer. Since glucose and insulin are of fundamental importance to all cells and tissues to survive, it is not surprising to note that some of 
the intermediate products of metabolism of glucose could be of benefit in a variety of clinical conditions. Pyruvic acid is an intermediate in the metabolism of glucose and is also a potent scavenger of free radicals. Several studies suggest that pyruvate has potent anti-oxidant and antiinflammatory actions (27). Furthermore, blueberry anthocyanins and the respective anthocyanin-pyruvic acid adducts demonstrated anticancer properties by inhibiting cancer cell proliferation and by acting as cell antiinvasive factors and chemoinhibitors (28). Citrate, one of the components of the Krebs cycle, has been reported to elevate the solubility of heavy metals by binding to heavy metal ions, and upon binding with zinc it may increase the bioavailability of zinc (29). In addition, similar to zinc, citrate is accumulated in normal prostatic cells at high concentrations, and the concentration has been found to be markedly decreased in prostate cancer cells (30). Prostate secretory epithelium has the capability of accumulating and secreting extraordinarily high levels of citrate, but citrate level is markedly decreased in prostate cancer (31). Thus, citrate shows similar characteristics to zinc in normal prostate and prostate cancer. Because of such characteristics, that would aid in the prevention and treatment of prostate cancer, interests in citrate are on the rise. A method (32) is disclosed for treating prostate cancer by administration of tartrate ions from a tartrate derivative. An important feature of the invention is the use of the L-tartrate ion as the prostatic acid phosphatase (PAP) inhibitor. The inhibitor will readily bind to the binding region of PAP and thus prevent other ions and compounds from doing so. Since in this study the treatments by CIZ did not significantly affect BW, effects on $\mathrm{PW} / \mathrm{BW}$ ratios can be attributed to effects on PW. How promising or clinically relevant are the effects of CIZ reported here remains to be answered. These results need to be reproduced, and higher doses and longer treatments need to be tested, and also in different models to determine whether it is worth assessing such effects in men with BPH.

\section{Conflict of interest}

The authors have no potential conflicts of interest.

\section{References}

[1] Ziada A, Rosenblum M \& Crawford ED. Benign prostatic hyperplasia: an overview. Urology 1999;53:1-6.

[2] Barnes J. Benign prostatic hyperplasia. Pharm J. 2002;269: $250-252$.

[3] Rohrmann S, Giovannucci E, Willett WC \& Platz EA. Fruit and vegetable consumption, intake of micronutrients, and benign prostatic hyperplasia in US men. Am J Clin Nutr. 2007;85:523-529.

[4] Willis MS \& Wians FH. The role of nutrition in preventing prostate cancer: a review of the proposed mechanism of action of various dietary substances. Clin Chim Acta 2003;330:57-83.
[5] Manac C, Scalbert A, Morand C, Remezy C \& Jimenez L. Polyphenols: food sources and bioavailability. Am J Clin Nutr. 2004;79:727-747.

[6] Middleton E, Kandaswami C \& Theoharides TC. The effects of plant flavonoids on mammalian cells: implications for inflammation, heart disease, and cancer. Pharmacol Rev. 2000;52:673-751.

[7] Liao S \& Hiipakka RA. Selective inhibition of steroid 5 alpha-reductase isozymes by tea epicatechin-3-gallate and epigallocatechin-3-gallate. Biochem Biophys Res Commun. 1995;214: 833-838.

[8] Antonelli F \& Beninati S. Enhanced survival of B16-F10 melanoma tumour-bearing C57BL6/N mice treated with a mixture of antioxidants in: Recent Res Devel in Life Sci. 2011;5:51-60 Research Signpost, Trivandrum India.

[9] Nilsson O, Peter A, Andersson I, Nilsson K, Grundstrom B \& Karlsson B. Antigenic determinants of prostate -specific antigen (PSA) and development of assays specific for different forms of PSA. Br J Cancer 1997;75:789-797.

[10] Bhargava, S, Canda, AE \& Chapple, CR. A rational approach to benign prostatic hyperplasia evaluation: recent advances. Curr. Opin. Urol. 2004;14: 1-6.

[11] Aryal M, Pandeya A, Gautam N, Baral N, Lamsal M, Majhi S, Chandra L, Pandit R \& Das BK. Oxidative stress in benign prostate hyperplasia. Nepal Med Coll J. 2007;9(4):222224.

[12] Noa M, Arruzazabala ML, Carbajal D, Más R \& Molina V.Effect of D-004, a lipid extract from Cuban royal palm fruit, on histological changes of prostate hyperplasia induced with testosterone in rats. Int $\mathrm{J}$ Tissue React. 2005;27(4):203-211.

[13] Araki H, Watanabe H, Mishina T \& Nakao M. High-risk group for benign prostatic hypertrophy. Prostate, $1983 ; 4: 253-264$.

[14] Lagiou P, Wuu J, Trichopoulou A, Hsieh CC, Adami HO \& Trichopoulos D. Diet and benign prostatic hyperplasia : a study in Greece. Urology, 1999;54: 284-290.

[15] Aryal M, Pandeya A, Gautam N, Baral N, Lamsal M, Majhi S, Chandra L, Pandit R \& Das BK. Oxidative stress in benign prostate hyperplasia. Nepal Med Coll J. 2007;9:222224.

[16] Wu F, Tyml K \& Wilson JX. Ascorbate inhibits iNOS expression in endotoxin- and IFN gamma-stimulated rat skeletal muscle endothelial cells. FEBS Lett. 2002;520:122126.

[17] Cindrova-Davies T, Spasic-Boskovic O, Jauniaux E, Charnock-Jones DS \& Burton GJ. Nuclear factor-kappa B, p38, and stress-activated protein kinase mitogen-activated protein kinase signaling pathways regulate proinflammatory cytokines and apoptosis in human placental explants in response to oxidative stress: effects of antioxidant vitamins. Am J Pathol, 2007;170:1511-1520.

[18] Bowie AG \& O'Neill LA. Vitamin C inhibits NF-kappa B activation by TNF via the activation of p38 mitogenactivated protein kinase. J Immunol. 2000;165:7180-7188.

[19] Gao P, Zhang H, Dinavahi R, Li F, Xiang Y, Raman V, Bhujwalla ZM, Felsher DW, Cheng L, Pevsner J, Lee LA, 
Semenza GL \& Dang CV. HIF-dependent antitumorigenic effect of antioxidants in vivo. Cancer Cell 2007;12:230-238.

[20] Nytko KJ, Spielmann P, Camenisch G, Wenger RH \& Stiehl DP. Regulated function of the prolyl-4-hydroxylase domain (PHD) oxygen sensor proteins. Antioxid Redox Signal 2007;9:1329-1338.

[21] Vissers MC, Gunningham SP, Morrison MJ, Dachs GU \& Currie MJ. Modulation of hypoxia-inducible factor-1 alpha in cultured primary cells by intracellular ascorbate. Free Radic Biol Med. 2007;42:765-772.

[22] Garland CF, Garland FC, Gorham ED, Lipkin M, Newmark $\mathrm{H}$, Mohr SB \& Holick MF. The role of vitamin D in cancer prevention. Am J Public Health, 2006;96: 252-261.

[23] Chen TC \& Holick MF. Vitamin D and prostate cancer prevention and treatment. Trends Endocrinol Metab. 2003;14:423-430.

[24] G.G. Schwartz GG \& Hulka BS. Is vitamin D deficiency a risk factor for prostate cancer? (Hypothesis). Anticancer Res. 1990;10:1307-1311.

[25] M.H. Ahonen MH, L. Tenkanen L, L. Teppo L, M. Hakama M, P \& Tuohimaa P. Prostate cancer risk and prediagnostic serum 25-hydroxyvitamin D levels (Finland). Cancer Caus- es Control 2000;11: 847-852.

[26] Tretli S, Hernes E, Berg JP, Hestvik UE, \& Robsahm TE. Association between serum 25(OH)D and death from prostate cancer. Br J Cancer. 2009:100:450-454.

[27] Undurti N. Das. Pyruvate is an endogenous anti-infl amatory and anti-oxidant molecule Med Sci Monit, 2006; 12(5): RA79-84.

[28] Faria A, Pestana D, Teixeira D, de Freitas V, Mateus N \& Calhau C. Blueberry anthocyanins and pyruvic acid adducts: anticancer properties in breast cancer cell lines. Phytother Res. 2010;24(12):1862-1869.

[29] Pabon M \& Lonnerdal B. Effect of citrate on zinc bioavailability from milk, milk fractions and infant formulas. Nutr Res. 1992;13:103-111.

[30] Costello LC \& Franklin RB. Novel role of zinc in the regulation of prostate citrate metabolism and its implications in prostate cancer. Prostate 1998; 35:285-296.

[31] Costello LC, Franklin RB \& Narayan P. Citrate in the diagnosis of prostate cancer. Prostate 1999; 38-237-245.

[32] Lebioda L \& Jakob CG. Treating prostate cancer with tartrate ions USA patent n. 5,763,490, 1998. 